\title{
PERAN ZAKAT DALAM OPTIMASI PORTOFOLIO INVESTASI ASET (Studi Kasus pada Bank Syariah Indonesia periode 2012-2014)
}

\author{
Ummay Mashithoh ${ }^{1)}$ \\ ummaymas@gmail.com \\ Universitas PGRI Madiun
}

\begin{abstract}
The basic concept of a portfolio is how to allocate a certain amount of funds to various types of investments that will produce optimal profits. This study aims to determine how the role of zakat in optimizing the asset investment portfolio. The research population is the Indonesian Islamic Bank registered at Bank Indonesia in the 2011-2015 period. Determination of samples in this study using a purposive sampling method. The results of the study state that the role of zakat has an optimal effect on Islamic investment. The advantage of investing in sharia with an optimum portfolio and incorporating the zakat element is far greater than the previous portfolio without adding the element of zakat to it. Keywords: portfolio, zakat, Islamic bank.
\end{abstract}

\begin{abstract}
ABSTRAK
Konsep dasar portofolio adalah bagaimana mengalokasikan sejumlah dana tertentu pada berbagai jenis investasi yang akan menghasilkan keuntungan yang optimal. Penelitian ini bertujuan untuk mengetahui bagaimana peran zakat dalam mengoptimalkan portofolio investasi aset. Populasi penelitian yaitu Bank Syariah Indonesia yang terdaftar di Bank Indonesia pada periode 2011-2015. Penentuan sampel dalam penelitian ini menggunakan metode purposive sampling. Hasil penelitian menyatakan bahwa peran zakat memberikan pengaruh yang begitu optimal bagi investasi syariah. Keuntungan berinvestasi syariah dengan portofoliooptimum dan memasukkan unsur zakat jauh lebih besar dari portofoliosebelumnya yang tanpa menambahkan unsur zakat kedalamnya. Kata kunci: portofolio, zakat, bank syariah
\end{abstract}

\section{PENDAHULUAN}

Saat ini investasi menjadi suatu hal yang sangat penting bagi setiap individu dalam menyimpan dananya dan untuk memperoleh tingkat keuntungan dari investasi tersebut, baik investasi di pasar uang maupun di pasar modal. Konsep dasar yang dinyatakan dalam portofolio adalah bagaimana mengalokasikan sejumlah dana tertentu pada berbagai jenis investasi yang akan menghasilkan keuntungan yang optimal (Harold,1998 (dalam Umanto,2008)).Tujuan portofolio adalah untuk menyebarkan atau mengurangi risiko investasi. Oleh karena itu kita perlu mencari portofolio optimal agar risiko dapat dikurangi yaitu bagaimana cara mendapatkan keuntungan dengan tingkat keuntungan maksimal dengan risiko tertentu atau menghasilkan tingkat keuntungan tertentu dengan risiko minimal. Dodi Tirtana (2009 menjelaskan dalam penelitiannya bahwa portofolio yang paling optimal yang dapat dibentuk dari 5 jenis kombinasi adalah portofolio dengan kombinasi 3 saham yaitu portofolio dengan kombinasi saham D (PT Bank Danamon Tbk),saham E 
(PT Bank Niaga Tbk) dan saham F Tbk), pada proporsi dana masingmasing $10 \%, 20 \%$ dan $70 \%$ menghasilkan expected return sebesar 0,27 atau $27 \%$ dan risiko (standar deviasi) sebesar 0,03 atau 3\%.Mario (2012) menyatakan bahwa investor dapat meningkatkan tingkat pengembalian investasinya dengan tingkat risiko yang sama dengan individual aset, tingkat risiko dapat dikurangi pada portofolio investasi yang sudah dibentuk. Sulton (2014) mengungkapkan bahwa terdapat perbedaan signifikan antara volume perdagangan 4 saham kandidat dengan 10 saham non kandidat portofolio. Rata-rata volume perdagangan saham kandidat lebih tinggi yaitu sebesar 29.703.050 dibandingkan rata-rata volume perdagangan saham non kandidat portofolio sebesar 23.225.161,83.

Investasi pada bank syariah juga tidak mengenal riba (bunga) dalam pembagian keuntungannya, melainkan sistem bagi hasil (nisbah) antara nasabah dan bank. Keuntungan yang diperoleh akan dibagi hasil sesuai dengan porsi yang telah disepakati antara bank dan nasabah.Dengan sistem pembagian keuntungan tersebut, maka besaran nilai hasil investasi terkadang tidak tetap. Karena besarnya nisbah tergantung pada keuntungan yang didapatkan bank dalam jangka waktu tertentu dan sesuai dengan kinerja. Alasan itulah yang akhirnya membuat beberapa orang enggan untuk menanamkan uangnya pada investasi syariah.

Dalam tiga tahun terakhir, topik investasi dana zakat merupakan topik penting yang menjadi perhatian para praktisi di kalangan lembaga zakat negara-negara Islam. Fenomena ini mengindikasikan betapa perkembangan ekonomi
(PT Bank Internanational modern yang menuntut adanya investasi dan pertumbuhan dana mulai mempengaruhi pola pikir para praktisi zakat karena zakat sebagai salah satu instrumen penting dalam peningkatan kesejahteraan umat, sehingga perlu dikelola lebih baik dan berdaya guna. (https://www.rumahzakat.org)Pertum buhan aset Perbankan Syariah pada tahun 2009 sampai 2010 selalu berada di atas $30 \%$, sedangkan pada tahun 2013 mengalami penurunan hanya sebesar $24.23 \%$, sehingga CAGR (Compound Annual Growth Rate) perbankan Syariah hanya di atas 30\% yang berarti 2 kali lipat dibandingkan pertumbuhan perbankan nasional. Dengan pangsa pasar yang masih kecil hanya sebesar $4.70 \%$ dari perbankan nasional (sampai Juli 2014) dan tingginya tingkat pertumbungan funding, financing, dan total asset, maka perbankan syariah di Indonesia merupakan pasar yang besar (huge market).

Meski mengalami peningkatan dari segi jumlah pembiayaan, semula Rp. 184 triliun pada Desember 2013 menjadi Rp. 187 triliun pada Juni 2014 namun pangsa pasar pembiayaan syariah sampai Juni 2014 justru mengalami penurunan dan baru mencapai $3.69 \%$ dari perbankan nasional. Hal tersebut juga terjadi terhadap presentase pertumbuhan pembiayaan bank syariah sampai Juni 2014 yang hanya sebesar 2.14\%, meskipun masih tersisa 1 semester untuk bank syariah meningkatkan growthnya, namun diperkirakan tidak akan mencapai pertumbuhan tahun sebelumnya. Dengan adanya ketidakstabilan pertumbuhan perbankan syariah apakah hasil peran zakat dalam 
portofolio investasi aset tetap optimal.

Shinta Rahmani (2009) mengungkapkanbahwa tanpa menerapkan ketentuan zakat, hasil yang diperoleh hanya return duniawi sebesar $17,34 \%$. Dengan menerapkan ketentuan zakat maka diperoleh return duniawi sebesar $15,1865 \%$ dan return uchrawi minimal sebesar $700 \times 2,9535 \%$, maka return investasi syariah dengan menerapkan ketentuan zakat akan jauh lebih besar.Penelitian Shinta ini yang menjadi acuan peneliti dalam melakukan penelitian, karena seperti yang diungkapkan bahwa masih sedikit bank baik konvensional

\section{Metode Penelitian}

Populasi dalam penelitian ini adalah Bank Syariah Indonesia yang terdaftar di Bank Indonesia pada periode 2011-2015. Penentuan sampel dalam penelitian ini menggunakan metode purposive sampling. Pada penelitian ini sample harus memenuhi beberapa kriteria berikut:

1. Bank Syariah di Indonesia yang terdaftar di Bank Indonesia.

2. Mengeluarkan laporan keuangan auditan selama periode 20112015.

3. Memiliki data yang dibutuhkan dalam penelitian secara lengkap.

4. Memiliki tahun buku yang berakhir 31 Desember. Hal ini dimaksudkan agar terjadi keseragaman waktu pelaporan keuangan.

Penelitian ini menggunakan maupun syariah yang menggunakan metode Markowitz dalam portofolio investasi. Penelitian ini merupakan replikasi penelitian Shinta Rahmani (2009) dengan mengubah sampel penelitian dari Unit Usaha Syariah Bank XYZ tahun 2006-2007 menjadi Bank Syariah Indonesia periode 2011-2015. Berdasarkan latar belakang di atas dan melihat fenomena investasi zakat yang terjadi di Indonesia saat ini maka peneliti mengambil judul "PERAN ZAKAT DALAM OPTIMASI PORTOFOLIO INVESTASI ASET (Studi Kasus pada Bank Syariah Indonesia periode 20122104)"

\section{Populasi dan Sampel}

metode pooled data, yaitu penggabungan antara cross section dan time series. Berdasarkan metode pooled data tersebut, maka diperoleh jumlah observasi sebanyak $15 \quad$ (3 sampel x 5 periode).

\section{Jenis dan Sumber Data}

Teknik Analisis Data

Teknik analisis data ini mengunakan metode Markowitz. Langkah-langkah yang digunakan dalam analisis data ini adalah sebagai berikut:

\section{Peghitungan Return yang Diharapkan (Expected rate of Return) \\ Expected return pada}

dasarnyamerupakan rata-rata tertimbang dari sejumlah return historis dengan probabilitamasingmasing return sebagaimana rumus berikut (Husnan 2015)

dimana :

$$
E(R i)=\sum_{J=1}^{M} P i j . R i j
$$

$\mathrm{E}(\mathrm{Ri})=$ Tingkat return yang diharapkan dari investasi $i$

$\mathrm{Pi}=$ Probabilitas memperoleh tingkat return pada investasi $i$ 
$\mathrm{Ri}=$ Tingkat return yang terjadi pada investasi $i$

$\mathrm{M} \quad$ = Banyaknya peristiwa yang mungkin terjadi

Return yang diharapkan ini tergantung dari tingkat keyakinan diukur dari return yang telah terjadi investor. Karena data historis return dikalikan probabilitas kemungkinan telah tersedia, maka expected return return yang akan diperoleh. dapat dicari dengan rumus berikut Probabilitas ini sifatnya subyektif (Husnan 2015)

dimana :

$$
E(r)=\frac{\sum_{i=1}^{N} R i}{N}
$$

$\mathrm{E}(\mathrm{Ri})=$ Return yang diharapkan dari investasi $i$

$\mathrm{Ri} \quad=$ Return yang terjadi pada investasi $i$

$\mathrm{N} \quad=$ Banyaknya peristiwa yang terjadi

a) Return pembiayaan murabahah dihitung dari rata-rata marjin tahunan selama periode penelitian (2011 sampai 2015)

b) Return pembiayaan istisna dihitung dari rata-rata marjin tahunan selama periode penelitian (2011 sampai 2015)

c) Return pembiayaan mudharabah dihitung dari rata-rata bagi hasil tahunan selama masa penelitian (2011 sampai 2015)

d) Return pembiayaan musyarakah dihitung dari rata-rata bagi hasil tahunan selama masa penelitian (2011 sampai 2015)

Setelah return dari masingmasing jenis investasi diketahui maka dihitung return portofolio investasi. Salah satu tujuan pembentukan portofolio adalah mendapatkan tingkat pengembalian yang rata-rata stabil. Tingkat pengembalian suatu portofolio merupakan rata-rata tertimbang dari tingkat pengembalian masing-masing jenis investasi. Return portofolio investasi dihitung menggunakan rumus penghitungan return portofolio:

dimana :

$$
E\left(R_{p}\right)=\sum_{s=1}^{n} r(s) \operatorname{Pr}(s)
$$

$\mathrm{E}(\mathrm{Rp})=$ Return portofolio yang diharapkan

$\mathrm{r}(\mathrm{s}) \quad=$ Return investasi $\mathrm{s}$

$\operatorname{Pr}(\mathrm{s})=$ Bobot investasi $i$

$\mathrm{N} \quad=$ jumlah instrumen investasi

\section{Penghitungan Risiko}

Rumus penghitungan risiko yang dipakai adalah rumus berikut (Husnan 2015)

dimana :

$$
\sigma^{2}=\frac{\sum_{i=1}^{N}[R i j-E(r i)]^{2}}{N}
$$

$\mathrm{Rij}=$ Return aset

$\mathrm{E}(\mathrm{ri})=$ Return yang diharapkan

$\mathrm{N}=$ Jumlah data 
Notasi $\sigma$ dalam statistik dikenal sebagai deviasi standar, yang merupakan ukuran

penyimpangan.

\section{Penghitungan Kovarian dan koefisien korelasi}

Kovarian adalah ukuran berapa banyak return dari dua aset berisiko bergerak bersamaan. Kovarians positif berarti imbal hasil aset-aset tersebut bergerak bersamaan yang berarti bila salah satu aset menghasilkan keuntungan maka aset

$\begin{aligned} & \text { Standar } \quad \text { deviasi } \\ & \sigma=\sqrt{\sum_{s=1}^{n}\left[\boldsymbol{r}_{s}-\boldsymbol{E}\left(\boldsymbol{r}_{s}\right)\right]^{2} \boldsymbol{P r}(\boldsymbol{s})}\end{aligned}=$

yang lain mengikuti, sedangkan kovarian negatif berarti aset-aset tersebut bergerak berlawanan yang berarti jika satu aset menghasilkan keuntungan, yang lain menanggung kerugian. Penghitungan kovarian akan dilakukan menggunakan rumus

dimana :

$$
\operatorname{Cov}\left(r_{1}, r_{2}\right)=\sum_{s} \operatorname{Pr}(s)\left[r_{1}-E\left(r_{1}\right)\right]\left[r_{1}-E\left(r_{2}\right)\right]
$$

$\operatorname{Pr}(\mathrm{s})=$ Probabilita

$\mathrm{r}_{1} \quad=$ Return aset 1

$\mathrm{E}\left(\mathrm{r}_{1}\right) \quad=$ Return yang diharapkan dari aset 1

$\mathrm{r}_{2} \quad=$ Return aset 2

$\mathrm{E}\left(\mathrm{r}_{2}\right)=$ Return yang diharapkan dari aset 2

Perhitungan kovarian ini, agar lebih mudah, akan dilakukan dengan menggunakan perangkat lunak excel.

dimana :

$$
\rho(1,2)=\frac{\operatorname{Cov}\left(r_{1}, r_{2}\right)}{\sigma_{1} \sigma_{2}}
$$

$\operatorname{Cov}\left(\mathrm{r}_{1}, \mathrm{r}_{2}\right) \quad=$ Kovarian dari return aset investasi 1 dan 2

\section{Pembentukan Portofolio Efisien}

Pembentukan portofolio efisien yang bergantung pada besarnya alokasi masing-masing aset investasi akan dilakukan menggunakan aplikasi solver yang terdapat dalam perangkat lunak Excel. Pembatasan yang dilakukan dalam pembuatan portofolio ini adalah :

a. Besarnya proporsi masing-masing jenis aset investasi $\geq 0$

\section{Penghitungan Reward to Variability}

$$
S=\frac{E\left(r_{p}\right)-r_{f}}{\sigma_{p}}
$$

dimana :
Sementara itu penghitungan koefisien korelasi akan dilakukan menggunakan rumus.

$\sigma_{1}=$ Standar
investasi 1eviasi
$\sigma_{2}$
investasi 2

b. Total bobot proporsi masingmasing jenis aset investasi adalah $100 \%$

c. Meminimumkan risiko (standar deviasi) portofolio

d. Besarnya return tertentu dimulai dari jenis investasi yang menghasilkan return terkecil sampai terbesar

Cara menghitung reward to variablitiy ratio dengan rumus :

$\mathrm{S}=$ Slope atau reward to variability

$\mathrm{r}_{\mathrm{f}} \quad=$ return aset bebas risiko

$\mathrm{E}\left(\mathrm{r}_{\mathrm{p}}\right)=$ return portofolio

$\sigma \mathrm{p} \quad=$ deviasi standar portofolio 
Angka terbesar dari hasil perhitungan persamaan diatas merupakan

\section{Zakat dan Total Aset}

Setelah berinvestasi selama 1 tahun, maka aset investasi tersebut merupakan harta kekayaan identik dengan uang tunai yang wajib zakat. Aset investasi tersebut kemudian

dimana :

$$
Z=2,5 \%\left(I_{0}+R\right)
$$

Sementara itu, hasil akhir dari aset setelah diinvestasikan secara syariah $T A=\left(I_{0}+R\right)-\left[2,5 \%\left(I_{0}+R\right) x 700\right]$ dimana :

\section{Hasil Penelitian dan Pembahasan}

Dari data yang peneliti peroleh, diketahui bahwa komposisi portofolio aset investasi Bank Syariah Indonesia selama tahun 2011-2015 rata-rata didominasi oleh pembiayaan murabahah. Pada bank BCA Syariah pembiayaan murabahah memiliki komposisi $50,06 \%$, sedangakan mudharabah dan musyarakah masing-masing hanya $9,71 \%$ dan $40,23 \%$.

Hal yang serupa juga terjadi pada bank Mega Syariah, dimana komposisi murabahah sebesar Bank BCA Syariah tingkat bagi hasil dan marjin pada masingmasing aset rata-rata $9,89 \%$ untuk murabahah, $10,34 \%$ untuk mudharabah dan $8,89 \%$ untuk musyarakah.Pada bank Mega Syariah rata-rata bagi hasil dan marjin adalah $19,65 \%$ untuk murabahah, $10,27 \%$

Perhitungan Rata-Rata Return dan Deviasi Standar

Pada bank BCA Syariah pembiayaan murabahah memiliki rata-rata return sebesar $9,89 \%$, sedikit diatas rata- kumpulan aset dari portofolio yang optimal.

dikurangkan zakat sebesar $2.5 \%$ dari modal pokok dan return yang diperoleh dengan rumus (HR Abu Daud):

$\mathrm{Z} \quad=$ besarnya zakat yang harus dikeluarkan

$\mathrm{I}_{0} \quad=$ Modal investasi syariah selama 1 tahun dihitung dengan rumus (QS. Al-Baqarah 261)

$\mathrm{TA}=$ total aset

Manajemen Portofolio Aset Bank Syariah Indonesia

99,03\% jauh lebih tinggi dibandingkan komposisi musyarakah yang hanya $0,92 \%$ dan mudharabah 0,05\%. Pada bank Mandiri Syariah murabahah tetap mendominasi komposisi portofolio dengan prosentase sebesar 73,28\%, kemudian dibawahnya ada musyarakah dengan komposisi $17,61 \%$, mudharabah $9,00 \%$ dan istishna $0,12 \%$.

\section{Perhitungan Return masing- masing Jenis Aset Investasi}

untuk mudharabah dan $13,56 \%$ untuk musyarakah. Sedangkan pada bank Mandiri Syariah perhitungan ratarata bagi hasil dan marjin diperoleh $11,20 \%$ untuk murabahah, $14,17 \%$ untuk mudharabah, $9,73 \%$ untuk musyarakah dan $10,19 \%$ untuk istishna.

rata return musyarakah yang hanya sebesar $8,89 \%$ dan sedikit berada di bawah rata-rata return muharabah 
yang memiliki rata-rata tertinggi yakni $10,34 \%$.Sementara pada bank Mega Syariah rata-rata return tertinggi berada di pembiayaan murabahah yakni sebesar 19,65\%, rata-rata returnterendah berada di pembiayaan mudharabah yang hanya sebesar 10,27\% dan di posisi tengah ada pembiayaan musyarakah yang memiliki rata-rata return sebesar $13,56 \%$. Hal ini berbeda dengan bank Mandiri Syariah, dimana ratarata returntertingginya terletak pada pembiayaan mudharabah yakni sebesar 14,17\%, sementara itu pembiayaan murabahah dan istishna memiliki rata-rata returnyang hampir sama yakni $11,20 \%$ dan $10,19 \%$, yang memiliki rata-rata returnterendah yaitu pembiayaan musyarakah yakni hanya sebesar 9,73\%.

Dari sisi risiko yang diwakili oleh besaran standar deviasi, masing-

\section{Perhitungan Koefisien Korelasi} Antar Jenis Investasi

Koefisien korelasi antara aset investasi pembiayaan murabaha dan mudharabah pada bank BCA Syariah bernilai 0.97345 . Ini berarti kedua aset tersebut memiliki lindung nilai yang positif, artinya kombinasi kedua aset tersebut akan menurunkan risiko investasi yang cukup baik pada kisaran return yang dapat diterima. Sedangkan hubungan pembiayaan murabaha dengan musyarakah nilainya berkisar antara 0,99915 nilai ini juga baik memberikan lindung nilai antar keduanya. Pembiayaan mudharabah dan murabahah mempunyai nilai koefisien korelasi sekitar $\quad 0,97345 \quad$ sedangkan pembiayaan mudharabah dan musyarakah memiliki niliai sebesar 0,98164 .

$\begin{array}{lrr}\text { Nilai } & \text { koefisien } & \text { korelasi } \\ \text { sebesar } & -0,72532 \text { terjadi } & \text { antara } \\ \text { pembiayaan } & \text { murabahah } & \text { dan }\end{array}$

masing bank tampak didominasi oleh pembiayaan murabahah, dimana pada bank BCA Syariah memiliki deviasi standar sebesar 55,14\%, bank Mandiri Syariah sebesar 91,51\% dan bank Mega Syariah memiliki risiko murabahah paling besar yakni $217,13 \%$. Sedangkan untuk risiko yang lain masing-masing bank memiliki besaran yang berbeda-beda, pada bank BCA Syariah risiko mudharabah sebesar $10,99 \%$ dan musyarakah sebesar 39,78\%. Berbeda dengan bank Mega Syariah dimana musyarakah memiliki risiko $1,09 \%$ dan mudharabah meiliki tingkat risiko terkecil yakni $0,18 \%$. Istishna pada bank Mandiri Syariah memiliki tingkat risiko paling kecil yakni hanya $0,09 \%$, sedangkan mudharabah dan musyarakah masing-masing memiliki risiko sebesar $13,93 \%$ dan $18,94 \%$.

mudharabah pada bank Mega Syariah, meskipun bernilai negatif tetapi hal ini menunjukkan bahwa kombinasi keduanya memberikan nilai portofolio yang sangat baik untuk memberi keuntungan returnrisiko yang diharapkan. Koefisien korelasi negatif lainnya juga terdapat pada murabahah dan musyarakah yakni sebesar -0,02387, pada kombinasi mudharabah musyarkah memiliki nilai sebesar $-0,67081$ kombinasi kedua aset investasi ini memberikan lindung nilai terbaik pada portofolio.

Pada bank Mandiri Syariah kombinasi antara murabahah dan mudharabah menghasilkan nilai 0,9927 hal ini lebih baik dibandingkan kombinasi murabahah dan istishna yakni $-0,94151$ serta murabahah dan musyarakah yang sebesar 0,99080. Kombinasi antara 
mudaharabah dan musyarakah memiliki nilai yang lebih tinggi dibandingkan mudharabah dan istishna yakni sebesar $-0,99458$ Perhitungan Kovarian Masingmasing Jenis Aset Investasi

Dari hasil penelitian diketahui bahwa aset-aset investasi yang memiliki kovariannegatif seperti pembiayaan murabahahdan mudarabah maupun murabahadan musyarakah pada bank Mega Syariah, serta kombinasi murabahah dan mudharabah, murabahah dan istishna, mudharabah dan musyarakah, serta musyarakah dan istishna pada bank Mandiri Syariah, akan memiliki nilai return yang bergerak berlawanan.Peningkatan return salah satu aset akan diikuti penurunan return aset lain yang menjadi kombinasinya. Hal ini

\section{Pembentukan Portofolio Aset Investasi}

Hasil penelitian terlihat bahwa dengan proporsi alokasi yang sama pada tiapaset investasi Bank BCA Syariah akan menghasilkan return portofolio sebesar $0,008 \%$ dan tingkatrisiko sebesar $0,004 \%$. Pada bank Mega Syariahmemiliki return sebesar $0,03 \%$ dan tingkat risiko sebesar $0,006 \%$, sedangkan pada bank Mandiri Syariah memiliki return sebesar $0,00004 \%$ dan tingkat risiko sebesar $0,00002 \%$.

Hasil menunjukkan bahwareturn terkecil pada Bank BCA Syariah dihasilkan oleh jenisasset investasi mudharabah sebesar $10,99 \%$, sehingga return ini merupakan returnterkecil yang akan akan dimasukkan dimasukkan pada solver. Sama dengan Bank BCA Reward to variability ratio dapat dilihat bahwa portofolio bank BCA Syariah yang memilikistandar dibanding $\quad 0,93685$. Kombinasi portofolio yang sangat baik juga dimiliki oleh musyarakah dan istishna yakni sebesar $-0,96814$.

terjadi pada seluruh matriks kovarian.

Bagi asset-aset investasi yang memiliki nilai kovarian positif, dipastikanakan memiliki return yang bergerak bersamaan, misalnya pembiayaanmurabahah dan mudharabah pada ban BCA Syariah. Jika pembiayaan murabahah mengalamipeningkatan return maka akan diikuti juga oleh peningkatan return pembiayaanmudharabah dan sebaliknya. Demikian juga bagi kombinasi asset lainnya.Perbedaannya hanya terdapat pada besarnya pergerakan tersebut, makin besarnilai kovarian maka makin besar pula pergerakan return antara aset-asetinvestasi tersebut

Syariah, Bank Mega Syariah memiliki returnterkecil pada aset mudharabah yakni sebesar $0,18 \%$, berbeda dengan yang lain pada bank Mandiri Syariah aset yang memiliki returnterendah justru Istishna yakni hanya sebesar $0,09 \%$.

\section{KurvaEfficient Frontier}

Grafik dalam penelitian menunjukkan bahwa kombinasi portofolio investasi pada masingmasing bank syariah dengan proporsi yang ada saat ini semua terletak pada garis efficient frontier, yang berarti bahwa portofolio asset investasi efisien, sehingga hasil yang didapat kemungkinan optimal.

Perhitungan Reward to Variability Ratio

deviasi atau risiko terendah sebesar 0,61639 terletak pada portofolioyang memiliki return sebesar 1,39004. 
Namun portofolio ini bukanlahpemilik nilai reward to variablitity ratio tertinggi, karena nilai tertinggi yaitusebesar 2,173901 dimiliki oleh portofolio yang memiliki standar deviasi sebesar 1,38356 dengan perolehan return

Pada bank Mega Syariah portofolio yang memilikistandar deviasi atau risiko terendah sebesar 0,08715 terletak pada portofolioyang memiliki return sebesar 0,12629 . Namun portofolio ini juga bukanlahpemilik nilai reward to Sedangkan bank Mandiri Syariah portofolio yang memilikistandar deviasi atau risiko terendah sebesar 0,00263 terletak pada portofolioyang memiliki return sebesar -0,00162. Akan tetapi portofolio ini juga bukanlahpemilik Titik optimal yang peroleh melalui perhitungan reward to variability ratiomemiliki return yang lebih rendah dari return aktual, maka perlu dicari lagikomposisi yang memiliki return yang sama dengan return aktual dengan standardeviasi yang lebih rendah atau dapat juga dicari standar deviasi yang sama untuktingkat return yang lebih tinggi.Bank BCA Syariah memiliki return sebesar 2,24888 dan risiko 0,99997, pada bank Mega Syariah memiliki risiko lebih besar daripada bank BCA Syariah yakni sebesar 0,19439 denga return 0,39726. Sedangkan pada bank Mandiri Syariah memiliki risiko sebesar 0,15005 dan return sebesar 0,33141.

Pengurangan Zakat dari Aset Investasi

Aset investasi yang dimiliki merupakan harta kekayaan yang wajib zakat sebesar 3,10771. Portofolio inimemiliki komposisi investasi asset pembiayaan istisna sebesar 0.00000 , pembiayaan murabaha 0,011991 , pembiayaan mudharabah 0,01505 dan pembiayaan musyarakah 0,02123 .

variablitity atio tertinggi, karena nilai tertinggi yaitusebesar 1,883848 dimiliki oleh portofolio yang memiliki standar deviasi sebesar 0,30163 dengan return sebesar 0,66822 .

nilai reward to variablitity ratio tertinggi, karena nilai tertinggi yaitusebesar 1,897297 dimiliki oleh portofolio yang memiliki standar deviasi sebesar 0,29747 dengan return sebesar 0,66444 .

jika telah melewati masa haul. Seorang muslim wajib hukumnya patuhpada hukum-hukum Islam yang tercantum pada Al Qur'an dan hadist. Begitujuga terhadap ketentuan zakat maal. Para ahli fiqih berpendapat bahwasurat berharga yang dimiliki, sebagai kompensasi atas uang yang diinvestasikandi bank syariah, dikategorikan sebagai asset keuangan nisabnya sebesar 85gremas dan besarnya zakat adalah 2,5\% begitupun surat berharga (financialsecurities), investment certificate dan insurance policy dikategorikan pada asetkeuangan.

Karena perhitungan investasi yang dilakukan pada penelitian ini adalahlima tahun, dengan demikian zakat yang dikurangkan besarnya $2.5 \%$ x 5 tahun dengan perhitungan sebagai berikut. 
$Z=2,5 \%\left(I_{0}+R-\sigma\right)$
Dari hasil perhitungan maka diperoleh hasil yang tertera pada tabel 4.1 dibawah ini:

Tabel 4.1

Total Optimal Aset Duniawi

\begin{tabular}{|c|c|c|c|c|c|}
\hline & $\begin{array}{c}\text { Asset } \\
\text { Investasi }\end{array}$ & Return & Risiko & $\begin{array}{c}\text { Besar } \\
\text { Zakat }\end{array}$ & Total \\
\hline Bank BCA Syariah & $5,18 \%$ & $224,89 \%$ & $100,00 \%$ & $12,50 \%$ & $16,26 \%$ \\
\hline Bank Mega Syariah & $4,10 \%$ & $39,73 \%$ & $19,44 \%$ & $12,50 \%$ & $3,05 \%$ \\
\hline $\begin{array}{c}\text { Bank Mandiri } \\
\text { Syariah }\end{array}$ & $-0,24 \%$ & $33,14 \%$ & $15,00 \%$ & $12,50 \%$ & $2,24 \%$ \\
\hline
\end{tabular}

Sumber : Laporan Keuangan Bank Syariah 2011-2015, data diolah

Sementara itu, hasil akhir dari

aset setelah diinvestasikan secara syariah selama 5 tahun dihitung dengan rumus (QS. Al-Baqarah 261)

\section{$T A=2,5 \%\left(I_{0}+R-\sigma\right) x 700$}

Hasil dari penggunaan rumus uchrowi maka hasil akhir total aset tertera pada tabel 4.2

Tabel 4.2

Total Aset Optimal Uchrowi

\begin{tabular}{|c|c|c|c|c|c|c|}
\hline & $\begin{array}{c}\text { Asset } \\
\text { Investasi }\end{array}$ & Return & Risiko & $\begin{array}{c}\text { Besar } \\
\text { Zakat }\end{array}$ & Total & Uchrowi \\
\hline $\begin{array}{c}\text { Bank BCA } \\
\text { Syariah }\end{array}$ & $5,18 \%$ & $224,89 \%$ & $100,00 \%$ & $12,50 \%$ & $16,26 \%$ & $11380,85 \%$ \\
\hline $\begin{array}{c}\text { Bank Mega } \\
\text { Syariah }\end{array}$ & $4,10 \%$ & $39,73 \%$ & $19,44 \%$ & $12,50 \%$ & $3,05 \%$ & $2134,10 \%$ \\
\hline $\begin{array}{c}\text { Bank Mandiri } \\
\text { Syariah }\end{array}$ & $-0,24 \%$ & $33,14 \%$ & $15,00 \%$ & $12,50 \%$ & $2,24 \%$ & $1566,19 \%$ \\
\hline
\end{tabular}

Sumber : Laporan Keuangan Bank Syariah 2011-2015, data diolah

Dalam penelitian ini menunjukkan bahwa investasi yang didalamnya ada unsur zakat memiliki nilai optimasi yang lebih besar daripada investasi yang tanpa menggunakan unsur zakat, hal ini terjadi sesuai dengan surat QS alBaqarahayat 261 dimana total kekayaan yang diinvestasikan pada produk investasi syariah dikalikan dengan 700, sehingga return uchrowi lebih optimal dibandingkan duniawi.

\section{KESIMPULAN}

Dari hasil analisis dan pembahasan mengenai pembentukan portofolio investasi pada pembiayaanmurabahah, pembiayaan mudharabah, pembiayaan musyarakah dan pembiayaan istishna pada bank Syariah Indonesia periode 2011-2015, maka kesimpulan yang dapat diambil yakni peran zakat memberikan pengaruh yang begitu optimal bagi investasi syariah. Keuntungan berinvestasi syariah dengan portofoliooptimum dan memasukkan unsur zakat jauh lebih besar dari portofoliosebelumnya 
yang tanpa menambahkan unsur

\section{SARAN}

\section{Bagi Perusahaan}

Bank Syariah Indonesia seharusnya menerapkan zakatpada aset investasi syariahnya, karena dengan menambahkan unsur zakat akan menambah nilai portofolio optimal pada perusahaan.

\section{Bagi Peneliti Selanjutnya}

Bagi peneliti selanjutnya diharapkan menambah variabel investasi lain seperti obligasi syariah untuk memperoleh nilai portofolio yang optimal. Serta bisa menambah periode penelitian agar memperoleh hasil yang lebih akurat.

\section{Daftar Pustaka}

Al Arif, Nur Rianto. 2013. Optimalisasi Peran Zakat DalamPerekonomian. UIN Syarif Hidayatullah Jakarta. Jakarta

Al-Qur'anul Karim

Eko Suprayitno, Radiah Abdul Kader dan Azhar Harun. 2013. The Impact Of Zakat OnAggregate Consumption In Malaysia.Journal of Islamic Economics, Banking and Finance. Malaysia

Eko, Umanto. 2008. Analisis dan Penilaian Kinerja Portofolio Optimal Saham-Saham LQ-45 . Universitas Indonesia. Jakarta

Euginia Natalia, Darminto, M.G Wi Endang NP. 2014. Penentuan Portofolio Saham Yang Optimal Dengan Model Markowitz Sebagai zakat kedalamnya.

DasarPenetapan Investasi Saham (Studi pada Perusahaan Food and Beverage yang terdaftar di Bursa Efek Indonesia Tahun 2012). Universitas Brawijaya. Malang

Hartono,Jogiyanto. 2010. Teori Portofollio Dan Analisis Investasi Edisi Kesembilan. Yogyakarta:BPFE

Ika Suprihatin, Budiyanto. 2014. Analisis Portofolio Saham Menggunakan Metode Markowitz Pada Perusahaan Retail yang Di Bursa Efek Indonesia. Sekolah Tinggi Ilmu Ekonomi Indonesia (STIESIA) Surabaya.Surabaya

Putra,Andika. 2014.Optimalisasi Peran Zakat dalam Pembangunan Ekonomi Menuju Indonesia yang Bermartabat. Jakarta

Rahmani, Shinta. 2008. Peran Zakat Dalam Optimasi Portofolio Aset Investasi (Studi Kasus pada Unit Usaha Syariah Bank $X Y Z$ ). UniversitasIndonesia. Jakarta

Siti Masitah Elias, Muhammad Zaim Razak dan Karmila Hanim Kamil. 2014. Investment Strategies in Malaysian Shariah-Compliant Equities with Transaction Costs.Universiti Sains Islam Malaysia. Malaysia 
Suad Husnan, 2015, Manajemen

Keuangan Teori dan

Penerapan (keputusan Jangka

Pendek), Edisi keempat, BPFE,

Yogyakarta

Sulton Bani Abdillah dan Sri

Rahayu. 2014. Analisis

Pembentukan Portofolio

Optimal Saham Menggunakan

Model Indeks Tunggal Untuk

Pengambilan Keputusan

Investasi (Studi Kasus Saham

Index LQ-45 di BEI Periode

Agustus 2008-Juli 2013).

Penelitian Universitas

Telkom:Jakarta

Sugiyono. 2015. Metode Penelitian

Kuantitatif, Kualitatif dan

R\&D. Bandung:Alfabeta

Tirtana,Dodi. 2009. Analisis Portofolio Optimal Investasi Saham Pada Sektor Perbankan Di Bursa Efek Indonesia Studi Kasus (2006-2008).
Universitas Gunadarma.

Malang

www.bcasyariah.co.id

www.bi.go.id

www.en.wikipedia.org

www.finansial.bisnis.com

www.id.wikipedia.org

www.ilmuekonomi.net

www.mandirisyariah.co.id

$\underline{\text { www.megasyariah.co.id }}$

www.novatihuta.blogspot.co.id

www.ojk.go.id

$\underline{\text { www.pusat.baznas.go.id }}$

www.rumahzakat.org 